\title{
Impact of a Speed-Controlled Water Pump on Power Line Communication of Smart Energy Meters
}

\author{
Muhammad Ammar Wibisono \\ University of Twente \\ Enschede, The Netherlands \\ Insittut Teknologi Bandung \\ Bandung, Indonesia \\ email: m.a.wibisono@utwente.nl
}

\author{
Niek Moonen \\ University of Twente \\ Enschede, The Netherlands
}

\author{
Bas ten Have \\ University of Twente \\ Enschede, The Netherlands \\ Deny Hamdani \\ Insittut Teknologi Bandung \\ Bandung, Indonesia
}

\author{
Waseem Elsayed \\ University of Zielona Gora \\ Zielona Gora, Poland
}

\begin{abstract}
Conducted electromagnetic interference cases are increasing due to the rapid increase of energy efficient electrical equipment in smart grids. For example static energy meter readings are interfered due to non-linear pulsed currents drawn by dimmed lighting technology and a speed-controlled water pump. A communication interface can be added to the static energy meter to form a smart meter, for example using power line communication which works in the CENELEC-A band. This paper shows that the interference from a water pump does not only interfere with the readings of static energy meters but also affects the power line communication of a smart meter. It is shown that the interfered and lost frames during communication are affected by the average impedance of the speed-controlled water pump.
\end{abstract}

Keywords-Conducted electromagnetic interference, nonlinear currents, power line communication, smart grid, smart meter.

\section{INTRODUCTION}

Recently, the use of the modern energy efficient electrical equipment is rapidly increasing with the development of the smart grid technology [1]. This equipment produces nonlinear, impulsive currents due to the cyclic switching mechanism and can disrupt the performance of many other equipment [2]. As a result, conducted electromagnetic interference (EMI) cases between electrical equipment in the frequency range between $2-150 \mathrm{kHz}$ is increasing [3]. Further, the lack of the civil standards also facilitates the increasing number of interferences between electrical equipment in this frequency range [4].

For example, static energy meters that measure the power consumption of consumers in a household situation are found to be interfered due to dimmed light equipment of light emitting diode (LED) or compact fluorescent lighting (CFL) technology [5] and a speed-controlled water pump [6]. Maximum misreading of $2675 \%$ were found experimentally [7]. The critical drawn currents in these cases are non-linear pulses with a high peak values, high crest factors and a high rising slopes.

The static energy meter can also be equipped with a communication link to send the power consumption data towards the data concentrator of the utility provider. This enables for a more efficient use of the electricity grid based on the supply and demand of energy in smart grid technology. The use of the power line communication (PLC) for the data transmission has gained interest because it offers a low cost solution for the communication by utilizing the existing power line network, which requires no additional transmission line or wireless network [8]. Therefore, this is also used in many smart meters throughout Europe, where PLC in the CENELEC-A band is used for communication [9].

The PLC which works in the CENELEC-A band is also one of the victims of the interference from non-linear equipment such as the energy efficient lamp. It has been shown that the increasing number of LEDs [10] and the pulse width of the current from the LEDs [11] can affect the performance of the PLC. The impact of the modulation of the switched-mode power supplies such as the power converter on the PLC has been observed and described in [12], and the impact of the transistors in the power converter are shown to affect the performance of the PLC modem [13].

In this paper it is shown that critical non-linear current waveforms from a speed-controlled water pump do not only interfere the static energy meter readings, but also affect the PLC of the smart meter. This is done by measuring the normal mode current of the water pump and observing its impact on the PLC which works at CENELEC-A band. The impact of the interference on the PLC is shown through the interfered and lost frames. The measurement is performed using a nondistorted mains supply to isolate the setup from the interference from the grid. Only PLC which works in the frequency below $150 \mathrm{kHz}$ is considered, as these frequencies are also used in smart meters, and in order to avoid the radiated emission and EMI issues toward wireless system [2].

The rest of this paper is structured as follows: Section II describes the method used to show the impact of the conducted EMI from the water pump on the PLC, followed by the resulting interfering signal and communication results from the PLC modem in Section III. Section IV discusses the findings of the experiments, and in Section $\mathrm{V}$ the work is concluded. 


\section{METHOD}

\section{A. Experimental setup}

In this section, the measurement setup to observe the impact of the conducted interference from the water pump on the PLC is described, using the setup shown in Fig. 1. An ideal $230 \mathrm{~V} 50 \mathrm{~Hz}$ mains supply was generated using a Cinergia GE-15 grid emulator to provide an undistorted mains voltage. A one-phase LISN was used to provide stable impedance during the measurement. Then two ATPL360-EK PLC modems from Microchip which work in the CENELECA band between $35-91 \mathrm{kHz}$ [14] are connected as transmitter and receiver of the communication data. Both modems are separated by 10 meter to minimize the attenuation of the cable. The transmitting modem is operated in high and low impedance load mode, where the high impedance mode corresponds to the artificial mains network described in [15] and the low impedance mode corresponds to [14]. This affects the modems transmitting power which is typical $1.5 \mathrm{~W}$ and $2.2 \mathrm{~W}$, respectively. The communication test was performed by sending 10000 data frames with 10 bytes of data, that have a duration of $17.9 \mathrm{~ms}$ and a mean receiving interval for each frame of $40 \mathrm{~ms}$. 8PSK modulation is used which gives the lowest frame length to minimize the probability of the data frames being interfered by the current pulses of the water pump in time domain. The setup is loaded with a speed-controlled water pump, which has 10 operation levels. The communication test is repeated for all these levels. The line current of the LISN ( $I_{\text {LISN }}$ ), the current of the PLC transmitter and receiver $\left(I_{\mathrm{TX}}\right.$ and $\left.I_{\mathrm{RX}}\right)$, and the line current of the water pump $\left(I_{\mathrm{L}}\right)$ are measured using TA189 current clamps from Picoscope. A differential probe model TA043 from Picoscope is used for measuring the differential mode voltage from the mains ( $\left.V_{\text {mains }}\right)$. A Picoscope 4824 is used as a digitizer to measure the currents and the voltages simultaneously using a multi-channel time-domain EMI approach [16].

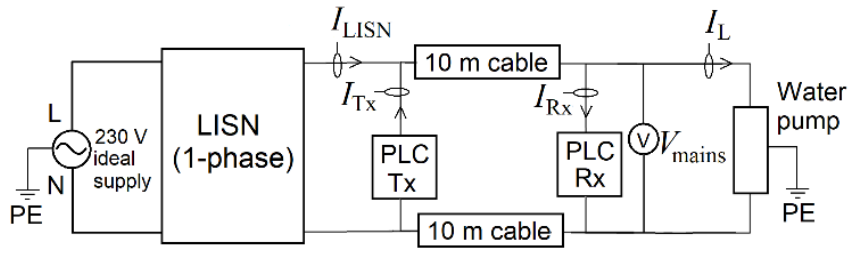

Fig. 1. Measurement setup.

\section{B. Description of the test signals}

The test signals as drawn by the different levels of the speed-controlled water pump are plotted in Fig. 2, it shows the average waveform during the complete measurement cycle. The time-domain parameters of the pulses are extracted using the parametric model from [17] and summarized in Table I. . It shows that the pulsed signals of level 1 to 9 have similar peak current value, while level 10 has significantly lower peak current. The main difference between level 1 to 9 is the phase firing angle of the current with respect to the voltage, which decreases for higher levels as is visible from Fig. 2. This means that level 10 of the water pump has the highest impedance compared to other levels as shown in Fig. 3. The water pump impedance decreases from level 9 to 1 due to the decreasing instantaneous mains voltage at the moment when the pulsed current appears.



Fig. 2. Current generated by the different levels of the water pump [18].

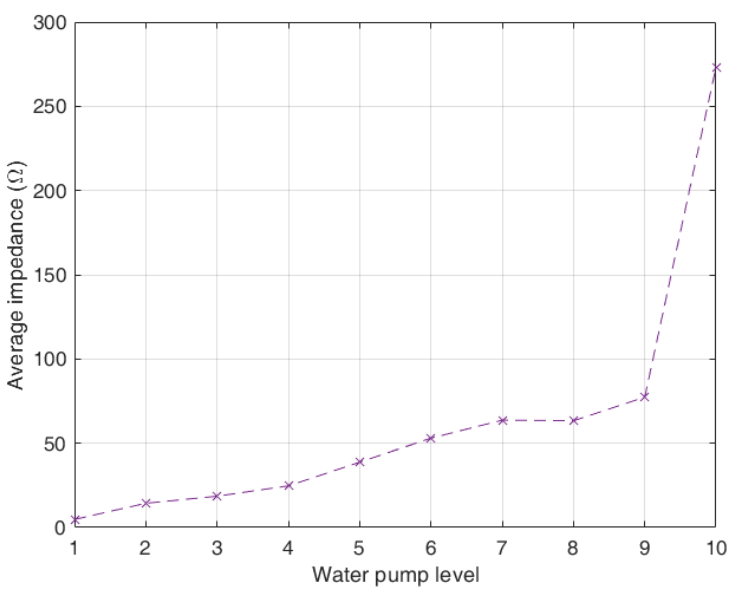

Fig. 3. Average impedance for each water pump level

TABLE I. TIME-PARAMETERS OF TEST SIGNALS, GENERATED BY DIFFERENT LEVELS OF THE SPEED-CONTROLLED WATER PUMP.

\begin{tabular}{|r|r|r|r|r|r|}
\hline Level & $\begin{array}{r}\text { Charge } \\
(\mathbf{m C})\end{array}$ & $\begin{array}{r}\text { Crest } \\
\text { factor }\end{array}$ & $\begin{array}{r}\text { Peak } \\
\text { value (A) }\end{array}$ & $\begin{array}{r}\text { Pulse } \\
\text { width (ms) }\end{array}$ & $\begin{array}{r}\text { Slope } \\
(\mathbf{A} / \boldsymbol{\mu} \mathbf{s})\end{array}$ \\
\hline 1 & 4.6 & 7.5 & 9.7 & 0.8 & 0.9 \\
\hline 2 & 4.8 & 7.4 & 9.9 & 0.8 & 0.9 \\
\hline 3 & 5.1 & 7.4 & 10.4 & 0.8 & 1.0 \\
\hline 4 & 5.3 & 7.3 & 10.7 & 0.8 & 1.1 \\
\hline 5 & 5.5 & 7.3 & 10.9 & 0.9 & 1.1 \\
\hline 6 & 5.8 & 7.2 & 11.0 & 1.0 & 1.0 \\
\hline 7 & 6.0 & 6.9 & 10.8 & 1.0 & 1.0 \\
\hline 8 & 6.2 & 6.7 & 10.5 & 1.0 & 1.0 \\
\hline 9 & 6.1 & 6.8 & 9.8 & 1.1 & 1.3 \\
\hline 10 & 6.4 & 4.9 & 5.4 & 2.9 & $3.3 \cdot 10^{-2}$ \\
\hline
\end{tabular}

\section{RESULTS}

\section{A. Conducted interference created by the water pump}

The current from the water pump at level 10 measured at the load, LISN, PLC transmitter (Tx), and receiver (Rx) is plotted in Fig. 4 and Fig. 5 for the high and low impedance mode of the PLC modem, respectively. Both plots show one pulse during communication and one pulse when there is no 
data transmitted, i.e. showing two periods at mains frequency. During low impedance mode the transmitted signal has a higher amplitude compared to the high impedance mode, as expected due to the higher transmitted power.

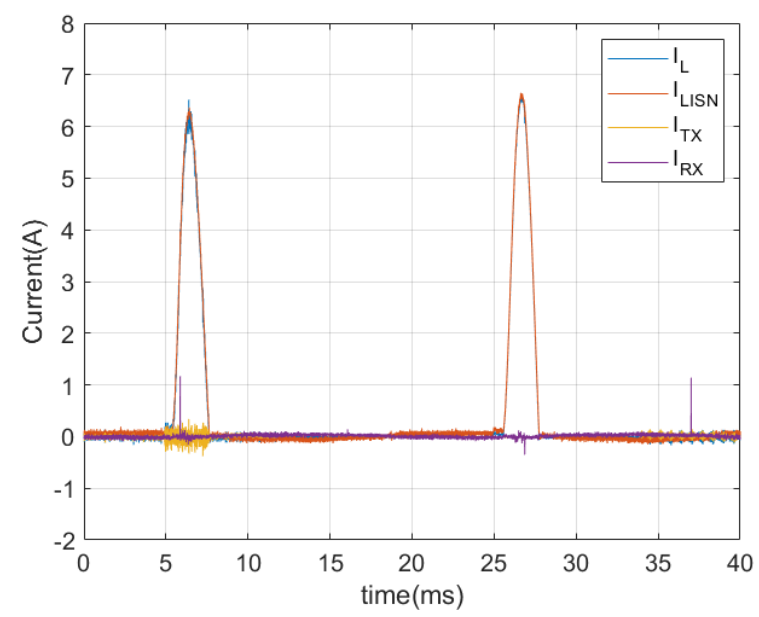

Fig. 4. Current from the water pump at level 10 measured at the load, LISN, Tx and Rx for high impedance mode of the PLC modem.

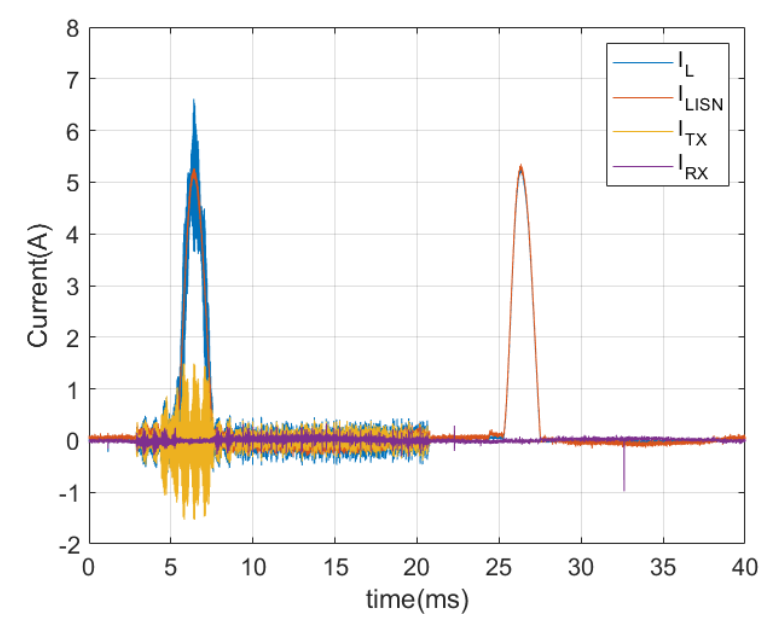

Fig. 5. Current from the water pump at level 10 measured at the load, LISN, Tx and Rx for low impedance mode of the PLC modem.

\section{B. Communication results of the PLC}

The resulting lost frames during the communication test are visualized in Fig. 6. For the high impedance mode, more frames are interfered and lost compared to the low impedance mode. This is straightforward as the impedance of the water pump, as shown in Fig. 3, matches the low impedance mode of the PLC better and thus more frames are lost in the high impedance mode. Consequently, for the high impedance mode, the highest percentage of interfered frames occurs at lower water pump levels. The trend shows that for the high impedance mode, the frame errors are decreasing with the water pump level, as the impedance of the water pump level increases with the water pump level, and thus matching the high impedance mode of the PLC. For the low impedance mode less deviation is visible, but the percentage of lost frames increases with the water pump level. Which could be explained by the lower impedance of the water pump at lower levels. Therefore, the higher levels do not match with the low impedance mode of the PLC anymore, and more frames are lost.

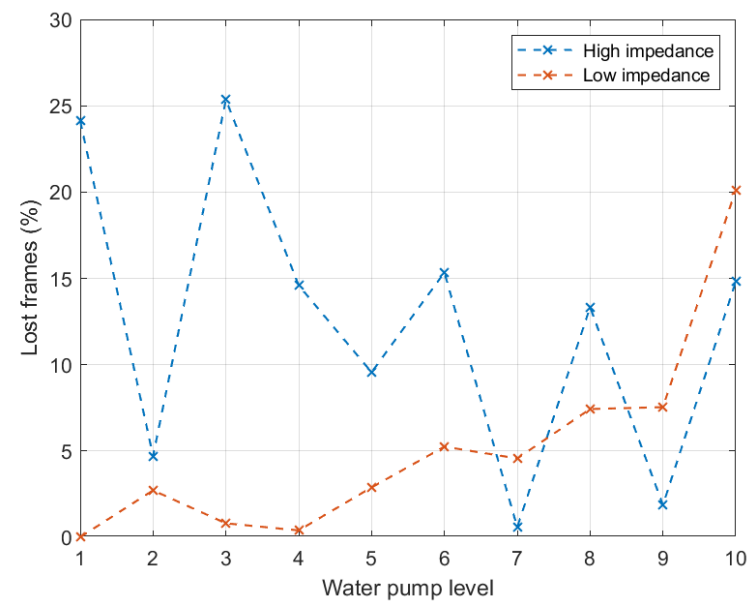

Fig. 6. Percentage of lost frames during the communication test.

\section{DISCUSSION}

The results obtained using the low impedance mode show that more frames are lost for water pump level 10, which is conversely of the previous reported static energy meter errors, where a decreasing level of the water pump results in higher errors [18]. However, this could be explained by the impedance of the water pump, as at level 10 the impedance is significantly higher compared to the other levels, as is visible in Fig. 3. Therefore, water pump level 10 is not matched with the low impedance mode of the PLC. As for the water pump level from 1 to 9 , the amplitude is significantly higher compared to the amplitude of the water pump level 10, thus it has a lower impedance compared to the water pump level 10. This is why the high impedance mode of the PLC shows higher frame errors trend for the lower water pump level, as it matches the higher water pump levels that have a higher impedance.

\section{CONCLUSION}

In this paper it is shown that the interference from a water pump that resulted in energy misreadings of smart meters can also affect the PLC of a smart meter. Measurements are performed using two different transmitting powers of the PLC modem to increase the power from high to low impedance mode, respectively. Interference from the speed-controlled water pump has shown to result in lost frames of the PLC modem. As a result, the PLC of a smart meter can also be disrupted besides the smart meter readings, which are proven to be interfered by the water pump in previous research. This can become problematic when using PLC for transmitting data to the utility provider. The obtained communication results show that when transmitting data at high impedance mode, the highest lost frames occur at the lowest water pump levels. This lowest level corresponds to interference pulses with the lowest impedance. For the low impedance mode however more frames are interfered and lost at the highest water pump level due to the higher impedance of the water pump.

\section{REFERENCES}

[1] M. Olofsson, "Power Quality and EMC in Smart Grid," in 2009 10th International Conference on Electrical Power Quality and Utilisation, Lodz, Poland, 2009. 
[2] CENELEC 205A, "Electromagnetic Interference between Electrical Equipment/Systems in the Frequency Range below $150 \mathrm{kHz}$," no. October, pp. 1-121, 2015.

[3] F. Leferink, "Conducted interference, challenges and interference cases," IEEE Electromagn. Compat. Mag., vol. 4, no. 1, pp. 78-85, 2015.

[4] B. J. A. M. Van Leersum, R. B. Timens, F. J. K. Buesink, and F. B. J. Leferink, "Time domain methods for the analysis of conducted interference on the power supply network of complex installations," IEEE Int. Symp. Electromagn. Compat., pp. 605-610, Gothenburg, Sweden, 2014

[5] F. Leferink, C. Keyer, and A. Melentjev, "Static energy meter errors caused by conducted electromagnetic interference," IEEE Electromagn. Compat. Mag., vol. 5, no. 4, pp. 49-55, 2016.

[6] Z. Marais, H. E. Van den Brom, G. Rietveld, R. Van Leeuwen, D. Hoogenboom, and J. Rens, "Sensitivity of static energy meter reading errors to changes in non-sinusoidal load conditions," 2019 International Symposium on Electromagnetic Compatibility (EMC Europe 2019), pp. 202-207, Barcelona, Spain, 2019.

[7] B. ten Have, T. Hartman, N. Moonen, and F. Leferink, "Inclination of Fast Changing Currents Effect the Readings of Static Energy Meters," 2019 International Symposium on Electromagnetic Compatibility (EMC Europe 2019), pp. 208-213, 2019.

[8] J. Lin, T. Pande, I. H. Kim, A. Batra, B. L. Evans, "Time-Frequency Modulation Diversity to Combat Periodic Impulsive Noise in Narrowband Powerline Communications," IEEE Trans. Commun., vol. 63, no. 5, pp. 1837-1849, 2015.

[9] Accenture, "The role of communication technology in Europe's advanced metering infrastructure." [Online]. Available: https://www.accenture.com/t20150523T042354 w /usen/_acnmedia/Accenture/ConversionAssets/DotCom/Documents/Global/PDF/Industries 15/AccentureRole-Communication-Technology-Europes-Advanced-MeteringInfrastructure.pdf. [Accessed: 05-Jan-2021].

[10] M. A. Wibisono, N. Moonen, and F. Leferink, "Interference of LED Lamps on Narrowband Power Line Communication," 2020 IEEE
International Symposium on Electromagnetic Compatibility \& Signal/Power Integrity (EMCSI), pp. 219-221, Reno, USA, 2020.

[11] M. A. Wibisono, T. Hartman, N. Moonen, D. Hamdani, and F. Leferink, "The Effect of the Current Pulse Width from LEDs on Narrowband Power Line Communication and its Analysis in Time and Frequency Domain," 2020 International Symposium on Electromagnetic Compatibility - EMC EUROPE, Rome, Italy, 2020.

[12] W. El Sayed, H. Loschi, R. Smolenski, P. Lezynski, and C. L. Lok, "Performance Evaluation of the Effect of Power Converters Modulation on Power line Communication," XIV Scientific Conference Control in Power Electronics and Electric Drive "SENE 2019", Lodz, Poland, 2019.

[13] W. El Sayed, P. Lezynski, and R. Smolenski, "Prospective Analysis of the effect of Silicon based and Silicon-Carbide based Converter on G3 Power Line Communication," 2020 International Symposium on Electromagnetic Compatibility - EMC EUROPE, Rome, Italy 2020.

[14] ITU-T Recommendations G.9901, "Narrowband Orthogonal Frequency Division Multiplexing Power Line Communication Transceivers", April 2014.

[15] CENELEC EN50065-1, "Signalling on Low-Voltage Electrical Installations in the Frequency Range $3 \mathrm{kHz}$ to $148.5 \mathrm{kHz}$ ", May 2011.

[16] T. Hartman, N. Moonen, and F. Leferink, "Evaluation of Multichannel Synchronous Conducted TDEMI Measurements for High Voltage Power Electronics," 2018 Int. Symp. Electromagn. Compat. (EMC Eur., pp. 839-843, Amsterdam, The Netherlands 2018.

[17] B. ten Have, M. A. Azpúrua, T. Hartman, M. Pous, N. Moonen, F. Silva, and F. Leferink, "Waveform Model to Characterize TimeDomain Pulses Resulting in EMI on Static Energy Meters," Submitted to: IEEE Transactions on Electromagnetic Compatibility, 2020.

[18] B. ten Have, T. Hartman, N. Moonen, C. Keyer, and F. Leferink, "Faulty Readings of Static Energy Meters Caused by Conducted Electromagnetic Interference from a Water Pump," Renew. Energy Power Qual. J., Santa Cruz de Tenerife, Spain, 2019. 